\title{
Cellulose Nanocrystals from Lignocellulosic Raw Materials, for Oxygen Barrier Coatings on Food Packaging Films
}

\author{
By Riccardo Rampazzo, ${ }^{1,3 \dagger}$ (D) Derya Alkan, ${ }^{1 \dagger}$ Stefano Gazzotti, ${ }^{2,3}$ \\ Marco A. Ortenzi, ${ }^{2,3}$ (D) Giulio Piva ${ }^{4}$ and Luciano Piergiovanni ${ }^{1,3}$ (D)* \\ ${ }^{1}$ DeFENS, Department of Food, Environmental and Nutritional Sciences, PackLAB Università degli Studi di Milano, \\ 20133, Milan, Italy \\ ${ }^{2}$ Department of Chemistry, Università degli Studi di Milano, 20133, Milan, Italy \\ ${ }^{3}$ CRC Materiali Polimerici (LaMPo), Department of Chemistry, Università degli Studi di Milano, 20133, Milan, Italy \\ ${ }^{4}$ SAF, Department of Agricultural and Forest Sciences, Università degli Studi di Palermo, 90128, Palermo, Italy
}

\begin{abstract}
Cellulose nanocrystals (CNCs) are unique, renewable top-down nano particles from which coatings with improved gas barrier properties and new functionalities can be prepared. In this paper, the potential for obtaining such high performing nanocrystals from low-cost lignocellulosic by-products or raw materials is proved by a comparison study on CNCs obtained both from cotton linters and kraft pulp, by means of the ammonium persulfate (APS) process. Morphological and chemical characterization of the nanocrystals obtained, as well as the main functional properties of the poly(ethylene terephthalate) coated films, showed quite similar characteristics and performances of CNCs obtained from pure cellulose raw material (cotton linters) and the nanoparticles produced from a potential discard of paper making processes (kraft pulp). In particular, the gas barrier properties of the coating produced with CNCs obtained from kraft pulp were very promising, providing oxygen and carbon dioxide permeability values hundreds of times lower than those of equal thickness in comparison with common barrier synthetic polymers, over a broad range of temperatures. The results obtained are relevant not only for the outstanding performances achieved, but also because they evoke a possible positive example of industrial symbiosis in the packaging field, merging together the requirements and needs of the paper and plastic industries and addressing the way towards a better management of waste and materials. Copyright @ 2017 John Wiley \& Sons, Ltd.
\end{abstract}

Received 6 September 2016; Revised 17 March 2017; Accepted 20 March 2017

KEY WORDS: film coating; gas permeability; cellulose nano-crystals; lignocellulosic materials; ammonium persulfate (APS) process

\section{INTRODUCTION}

Over the years, cellulose has been widely and commonly used for industrial purposes in general and in packaging applications in particular, due to its availability, biodegradability and mechanical properties. ${ }^{1}$ Cellulose is the main constituent of higher plants tissues and is also found in marine animals (tunicates), in algae, fungi, bacteria and invertebrates in small quantities. ${ }^{2}$ As well as in natural resources, however, it is also hugely abundant in a number of waste biomasses, industrial by-products, recycling streams and rubbish. ${ }^{3,4}$ From a chemical point of view, it is a linear polysaccharide formed by a chain of $\beta-1,4$ linked D-glucose where each subsequent glucose molecule is inverted $180^{\circ}$; therefore, the fundamental unit is frequently taken to be cellobiose, a dimer of glucose. The degree of glucose polymerization in cellulose is found in the range of 3000-15 000, corresponding to quite

\footnotetext{
* Correspondence to: Luciano Piergiovanni, DeFENS, Department of Food, Environmental and Nutritional Sciences, PackLAB Università degli Studi di Milano, Via Celoria 2, 20133 Milan, Italy.

E-mail: luciano.piergiovanni@unimi.it

†These authors contributed equally to this study
} 
high molecular weights. Hydrogen bonds and van der Waals forces between hydroxyl groups and oxygen atoms within cellulose molecule chains cause the formation of elementary fibrils which are further aggregated into larger microfibrils and cellulose fibres. Microfibrils, generally within $5-50 \mathrm{~nm}$ in diameter and several micrometers in length, have crystalline and amorphous regions. Because of the susceptibility of these amorphous regions of cellulose microfibrils to different treatments, they are selectively hydrolysed under optimized conditions. With the removal of the cellulose's amorphous parts, highly ordered structures, the cellulose nanocrystals (CNCs), can be extracted. Cellulose nanocrystals have different geometrical dimensions depending on the source of cellulosic material and hydrolysis conditions, but they are within $2-20 \mathrm{~nm}$ in width and generally hundreds of nanometres in length. ${ }^{5,6}$ At nanoscale dimensions, while maintaining low densities, biodegradability and low eco-toxicological characteristics, CNCs show excellent mechanical and barrier properties which expand their potential use in different applications, making them very attractive for packaging applications ${ }^{7,8}$; in particular, their good oxygen barrier properties have already been demonstrated as coatings and composites' constituents. ${ }^{9,10}$

Therefore, the extraction of CNCs from lignocellulosic sources is of great interest, taking into account the high availability and low cost of such cellulosic materials in underused by-products and wastes. A promising process useful for this goal is the ammonium persulfate (APS) process proposed by Leung et al. ${ }^{11}$ and recently checked for its capability in CNC production from cotton linters (CLs), in a comparison trial with the traditional sulphuric acid method. ${ }^{12}$ Ammonium persulfate, a strong oxidizing agent with high water solubility, is able to produce carboxylated CNCs having high crystallinity and active carboxyl groups, ${ }^{11}$ without special pre-treatments and in a relatively short time. When the solution of APS is heated, free radicals are produced, and hydrogen peroxide is also formed in the media under the acidic conditions. These chemicals are able to break down amorphous cellulose and produce carboxylated CNCs, but, at the same time, they can destroy lignin and other possibly contaminants in the raw materials used. ${ }^{13}$ Moreover, the conversion of the hydroxyl groups to the carboxylate form offers active sites for enhancing the adhesion onto coating substrates in order to produce new high performing, but more sustainable multilayer materials for critical packaging applications.

Lignocellulosic materials basically consist of three biopolymers, i.e. cellulose, hemicellulose and lignin and, depending on their source, they may be highly contaminated by various other substances. Therefore, the obtaining of high purity crystalline nanoparticles, suitable for the coating process and able to adequately performing as flexible packaging materials, must be thoroughly tested case by case. The main goal of this paper is to evaluate the possibility of producing CNCs from lignocellulosic by-products and wastes from the pulp and paper industries, with the aim of producing a bio-based, high gas barrier coating, which will be useful to improve a fundamental property of flexible packaging materials for sensitive foods, while enhancing their general sustainability. As a prototype of such by-products, we selected a kraft pulp (KP) rich in hemicellulose content and with a medium amount of lignin, comparing the final properties obtained with those of CNCs coming from quite a pure source, such as CLs, with a special focus on the gas permeability properties.

\section{MATERIALS AND METHODS}

\section{Materials}

Cotton linters (CLs) used as raw material to produce CNCs were kindly supplied by Innovhub (Milan, Italy), while unbleached hardwood KP was kindly supplied by Burgo Group (Altavilla Vicentina, Italy) (Figure 1). Ammonium persulfate $\geq 98 \%$, hydrochloric acid $37 \%$, sodium hydroxide $\geq 97 \%$ and the other chemicals used were purchased from Sigma-Aldrich (Milan, Italy). Poly(ethylene terephthalate) (PET) film, having a thickness of $12 \pm 0.5 \mu \mathrm{m}$, was provided by Sapici spa (Cernusco sul Naviglio, Italy).

\section{Kraft pulp characterization}

The pulp was initially delignified to remove the soluble lignin. ${ }^{14}$ To a $10 \mathrm{~g}$ KP sample, $320 \mathrm{ml}$ of hot distilled water, $2 \mathrm{ml}$ acetic acid and $4 \mathrm{~g}$ of sodium chlorite were added. The sample was heated to $70^{\circ} \mathrm{C}$ 

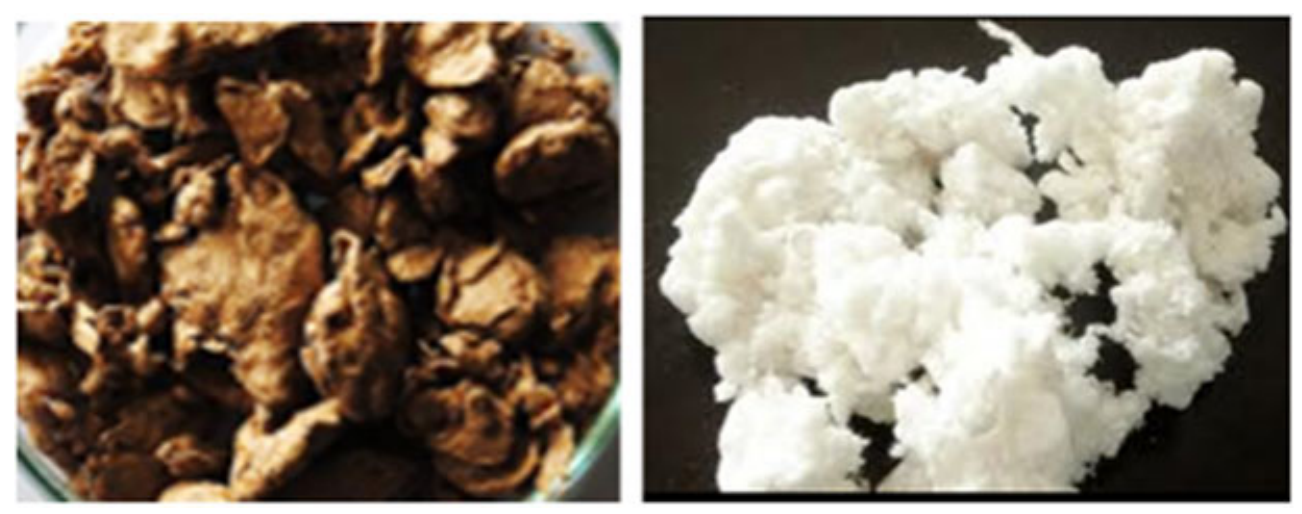

Figure 1. The raw materials used to obtain CNCs: Cotton linters (right), kraft pulp from hardwood (left).

and, after $60 \mathrm{~min}, 0.5 \mathrm{ml}$ of acetic acid and $1 \mathrm{~g}$ of sodium chlorite were slowly added to further continue the delignification process. An additional $0.5 \mathrm{ml}$ of acetic acid and $1 \mathrm{~g}$ of sodium chlorite were added to the solution every hour until the fibres were completely separated from the lignin. The delignification process performed lasted $4 \mathrm{~h}$ with three additions and $1 \mathrm{~h}$ without further addition, before vacuum filtration. The holocellulose obtained was then washed with acetone, air dried and stored in dry conditions.

Determination of $\boldsymbol{\alpha}$-, $\boldsymbol{\beta}$ - and $\boldsymbol{\gamma}$-cellulose. The Technical Association of the Pulp and Paper Industry (TAPPI) T 203 method $^{15}$ was used; $1.5 \mathrm{~g}$ of holocellulose obtained from the delignification process was extracted consecutively with $17.5 \%$ and $9.45 \% \mathrm{NaOH}$ solutions at $25^{\circ} \mathrm{C}$. The soluble fraction, consisting of $\beta$ and $\gamma$ cellulose, was determined volumetrically by oxidation with potassium dichromate solution, while $\alpha$ cellulose is estimated as the insoluble fraction derived by difference.

Lignin content and kappa number. Acid insoluble lignin content determination was performed following the technical report NREL/TP-510-42618. ${ }^{16}$ The Kappa number estimate was according TAPPI T 236 method. ${ }^{17}$

\section{Cellulose nanocrystal extraction by ammonium persulfate treatment}

The CNCs were obtained from CLs (CL-CNCs) and KP (KP-CNCs) by the hydrolyzing-oxidative method proposed by Leung and coworkers ${ }^{11}$ in 2011. Milled CLs or water swollen KP were introduced into a large beaker together with $1 \mathrm{M}$ APS for Cotton and $1.5 \mathrm{M}$ for KP. The ratio between fibres and APS solution was always 10:1 g/l, and the beaker was put onto a magnetic stirrer hotplate, equipped with a Vertex Digital thermoregulator (VELP Scientifica, Usmate, Italy). The mixture was heated and stirred at $75 \pm 2^{\circ} \mathrm{C}$ for $16 \mathrm{~h}$, limiting the evaporation by means of an aluminium foil cover. The suspension of CNCs obtained was centrifuged at $10000 \mathrm{rpm}$ for $15 \mathrm{~min}$. The centrifugation and a washing step with deionized water were repeated 4 times until the $\mathrm{pH}$ of the suspension was around 4 . Then, $\mathrm{NaOH} 1 \mathrm{M}$ was added until the suspension reached $\mathrm{pH} 8$ in order to have the sodium form of CNCs. After that, they were sonicated for $10 \mathrm{~min}$ ( 0.7 cycles, $70 \%$ output). The purified suspensions were frozen at $-18^{\circ} \mathrm{C}$ overnight and freeze-dried and then stored in dry conditions. The yields of CNC production (\%) were evaluated from the weight of the freeze dried products, by comparing them with the mass of cellulosic raw materials treated with APS. The freeze dried CNCs had an activity water (aw) in the range 0.15 and 0.35 , depending on the process and the temperature.

\section{Cellulose nanocrystal morphological characterization}

Drops of aqueous dispersions of CNCs $0.5 \% \mathrm{w} / \mathrm{w}$ were deposited on carbon-coated grids for transmission electron microscope (TEM) observations, negatively stained with uranyl acetate and then 
allowed to dry. The samples were analysed with a microscope operating at an accelerating voltage of $80 \mathrm{kV}$ (mod. Jeol-10084 Hitachi, Brugherio, Italy). Eight representative micrographs were selected for measuring the dimensions of nanocrystals by means of digital image analysis (Image-Pro Plus software). Scanning electron microscopy (SEM) images were also obtained from a Sigma Field Emission microscope (Carl Zeiss Microscopy LLC, Thornwood, NY) at accelerating 5-kV voltage and 6-mm working distance, with a 30-m width slit. The samples were first gold sputtered (Sputtering Polaron E 5100) for $30 \mathrm{~s}$ (rate $1 \mathrm{~nm} \mathrm{~s}^{-1}$ ) with argon and 18-mA current intensity.

In addition, by dynamic light scattering (DLS) measures (mod. Litesizer 500, Anton Paar, Graz, Austria), the equivalent hydrodynamic diameters CNCs were determined, as well as polydispersity index and an intensity weighted size distribution. The measurements were repeated on five different samples and performed at $25.0 \pm 0.1^{\circ} \mathrm{C}$ with a $35-\mathrm{mW}$ laser diode light $(\lambda=658 \mathrm{~nm})$ and collecting the scattered light at $90^{\circ}$. Prior to DLS measurement, the samples were diluted to 1:500 (w/w) with distilled water that was previously adjusted to $\mathrm{pH} 8$ and maintained at $25^{\circ} \mathrm{C}$ through stirring until measurement. Four millilitres of the diluted solution was poured in the measurement cell after 30-s homogenization by an ultrasonic water bath.

\section{Zeta-potential and conductivity of the cellulose nanocrystals}

Zeta potential of $\mathrm{CNCs}$ in the diluted suspension at $\mathrm{pH} 8$ was determined by electrophoretic light scattering (ELS), using the PALS technology (mod. Litesizer 500, Anton Paar, Graz, Austria). Measures were replicated 5 times, at $25.0 \pm 0.1^{\circ} \mathrm{C}$, by means of a $35-\mathrm{mW}$ diode laser $(\lambda=658 \mathrm{~nm})$ and at $15^{\circ}$ detection angle. The same measures give the values of conductivity $\left(\mathrm{mS} \mathrm{cm}^{-1}\right)$.

Fourier transform infrared (FTIR) spectra of the cellulose nanocrystals for the estimate of oxidation degree $(D O)$ and the evaluation of lignin removal

Fourier transform infrared spectroscopy was performed using an instrument (mod. Spectrum 100, Perkin Elmer, Milano, Italy) equipped with an attenuated total reflectance accessory (ATR). Spectra were collected using 64 scans with a resolutions of $4 \mathrm{~cm}^{-1}$, at room temperature, to estimate DO by rationing the carbonyl peak intensity (absorbance bands at $1735 \mathrm{~cm}^{-1}(v(\mathrm{C}=\mathrm{O})$ in the acid form) to that of the band near $1060 \mathrm{~cm}^{-1}$ (related to the backbone structure of cellulose). The equation used is the following ${ }^{18,19}$ :

$$
D 0=0.01+0.7\left(\frac{I_{1735}}{I_{1060}}\right)
$$

The effectiveness of lignin removal was evaluated by the disappearance or the reduction of the absorbance peaks in the wavenumber range pertinent to the lignin structure. ${ }^{20}$ Peak around $2850 \mathrm{~cm}^{-1}$ is characteristic of $\mathrm{C}-\mathrm{H}$ stretch of lignin methoxy groups. In the $2950-2850 \mathrm{~cm}^{-1}$ region, $\mathrm{C}-\mathrm{H}$ stretch of methyl and methylene groups are visible. Moreover, aromatic skeletal vibrations of carbon-carbon double bond of lignin were checked at $1510 \mathrm{~cm}^{-1}$, while the unconjugated carbonyl stretching at $1696 \mathrm{~cm}^{-1}$ was also used to identify lignin and other related compounds with benzene ring or double bond.

\section{Molecular mass of the cellulose nanocrystals by static light scattering (SLS)}

The molecular mass of the CNCs was estimated by measuring static light scattering (mod. Litesizer 500, Anton Paar, Graz, Austria). The intensity of the scattered light is directly related to molecular mass, and the scattering intensity of three different concentrations $(0.01,0.1,1 \mathrm{mg} / \mathrm{ml}$ in water at $\mathrm{pH}$ 8.0) was measured at $25^{\circ} \mathrm{C}$ and at $90^{\circ}$ detection angle. Toluene was used as reference, and the hydrodynamic radius detected by DLS measures was applied. The Debye $\operatorname{plot}^{21}$ was then generated; the intercept of each provided the weight-average molecular mass estimate. 


\section{Viscosity of cellulose nanocrystal dispersion}

In order to determine the rheological properties of CNC suspensions, frequency sweep experiments were conducted, using a rotational rheometer (mod. Physica MCR 300, Anton Paar, Graz, Austria) with cone-plate geometry $\left(\phi=50 \mathrm{~mm}\right.$, cone angle $=2^{\circ}$, minimum distance between plates $=50$ $\mu \mathrm{m})$. Strain was set equal to $5 \%$, and curves of complex viscosity as function of frequency were recorded. Thirty points were taken ranging from 100 to $0.1 \mathrm{~Hz}$ with logarithmic progression at $20^{\circ} \mathrm{C}$.

\section{Thermogravimetric analysis (TGA) of the cellulose nanocrystals}

Thermogravimetric analysis was carried out to compare the thermal stability of the two different kinds of CNCs using a thermogravimetric analyser (mod. TGA 4000, Perkin Elmer, Milano, Italy). Samples were heated from 30 to $600^{\circ} \mathrm{C}$ under air and at a heating rate of $10^{\circ} \mathrm{C} \mathrm{min}{ }^{-1}$. Three characteristic temperatures were measured: the onset temperature (To), the inflection point ( $\mathrm{Ti}$ ) and the maximum temperature related to significant weight loss (Tmax).

\section{Coating process}

An $8 \%(w / v)$ of CL-CNCs in water $(\mathrm{pH}=8)$ was coated onto PET 12- $\mu \mathrm{m}$ films, following the ASTM D823-07, practice C. Due to high viscosity, two subsequent coatings of $4 \% \mathrm{KP}-\mathrm{CNC}$ were accomplished on the same substrate. The CNC dispersions were previously sonicated for $20 \mathrm{~min}$ (1.0 cycles, $100 \%$ output). The side of the PET substrates receiving the coating was activated immediately before coating by a corona treatment (Arcotech $\mathrm{GmbH}$, Monsheim, Germany). The coatings were performed by an automatic film applicator (mod.1137, Sheen Instruments, Kingston, UK) at a constant speed of $2.5 \mathrm{~mm} \mathrm{~s}^{-1}$. Water was evaporated using a constant mild air flow $\left(25 \pm 0.3^{\circ} \mathrm{C}\right.$ for $\left.5 \mathrm{~min}\right)$.

\section{Thickness of the coatings}

The measurement of coating thickness was accomplished by a gravimetric method. Four $10 \times 10 \mathrm{~cm}^{2}$ samples (PET films coated by the two kinds of CNCs) were cut and weighed $\left(m_{1}, \mathrm{~g}\right)$. The coating was then removed by running hot water $\left(\sim 70^{\circ} \mathrm{C}\right)$, and the resulting bare film was dried and weighed $\left(m_{2}, \mathrm{~g}\right)$. The coating thickness $(L, \mathrm{~cm})$ was calculated according to the following equation:

$$
L=\frac{\left(m_{1}-m_{2}\right)}{\rho \times 100}
$$

where $\rho \sim 1.58 \mathrm{~g} \mathrm{~cm}^{-3}$ is the density of CNCs. ${ }^{22}$

\section{Water resistance of the coatings}

The water resistance of the coatings was determined by using an empirical test, measuring the mass solubilized after 4 days of immersion in a water bath at $37 \pm 0.5^{\circ} \mathrm{C}$, of samples $\left(10 \times 10 \mathrm{~cm}^{2}\right)$ cut from the two CNCs coated PET films. Four samples of the two kinds of CNCs (CL and KP) coated films were submerged in water, avoiding any floating, then wiped, dried for one day at room temperature, and weighed to measure the weight loss $(\%)$.

\section{Optical properties}

The transmittance of the coated films was measured at $550 \mathrm{~nm}$, according to the ASTM D 1746-70, by means of a UV-VIS spectro-photometer (mod. L650, Perkin-Elmer Milano, Italy). The haze (\%) of the same samples was measured according to ASTM D 1003-61 with the same instrument equipped with a 150-mm integrating sphere. Each sample was replicated three times, analysing four spots on each replicate (12 measures). 


\section{Contact angles and surface energies}

Static contact angles of the substrate (uncoated PET film after the corona treatment) and the coated films were determined by using an OCA 15 Plus angle goniometer (Data Physics Instruments GmbH, Filderstadt, Germany). Milli-Q water (18.3 $\mathrm{M} \Omega \mathrm{cm})$, formamide and apolar diiodomethane (99\%) were used to assess and characterize surface free energies (SFE). On the basis of the surface tension parameters of the liquids used (Table 1), the polar $\gamma_{s}^{P}$ and dispersive $\gamma_{s}^{D}$ parts of SFE were calculated by the Owens-Wendt-Rabel and Kaelblem (OWRK) method. ${ }^{23,24}$ The sessile drop method was used, by gently dropping a droplet of $4.0 \pm 0.5 \mu \mathrm{l}$ of each liquid onto the substrate. The measurements were performed at room temperature (RH about $40 \%$ ) on five different positions for each sample. The equilibrium angle was achieved in 2-3 s and remained constant for at least 10-15 s; due to the short time of measurement, we assume that the CNC coating did not change its original activity water value which was about 0.34 . The instrument was equipped with a highresolution CCD camera and a high performance digitizing adapter. SCA20 and SCA21 software (Data Physics Instruments GmbH, Filderstadt, Germany) were used, respectively, for contact angle measurements and surface energy calculation.

\section{Coefficient of friction}

The friction coefficients $(\mathrm{COF})$, both static $\left(\mu_{\mathrm{S}}\right)$ and dynamic $\left(\mu_{\mathrm{D}}\right)$ were measured by a dynamometer (mod. Z005, Zwick Roell, Ulm, Germany), on four different samples for each CNC type. The uncoated side of CNC-coated films was tightly wrapped onto a sled $\left(6.2 \times 6.2 \mathrm{~cm}^{2}, 197.99 \mathrm{~g}\right)$, while the un-treated side of uncoated PET film was covered on the sliding plane. Then, the sled was connected to the force sensor of a dynamometer and horizontally pulled by the instrument on the covered sliding plane. The pulling force data were recorded and analysed by TestXpert software V10.11 (Zwick Roell, Ulm, Germany), according to the standard method ASTM D 1894-87.

\section{Gas permeability}

All the gases permeability measures were performed by an isostatic permeabilimeter (mod. Multiperm, PERMTECH S.r.l., Pieve Fosciana, Italy) according to ASTM standard methods (D-3985 and F-1249, respectively). The oxygen and carbon dioxide permeability $\left(\mathrm{P}_{\mathrm{O} 2}, \mathrm{P}_{\mathrm{CO} 2}, \mathrm{ml} \mathrm{m}^{-2} \mathrm{~d}^{-1} \mathrm{bar}^{-1}\right)$ of uncoated PET film and KP-CNCs coated film was measured at 30, 34, 38, 42, 46 and $50^{\circ} \mathrm{C}$ at $0 \% \mathrm{RH}$. The permeability coefficients of the $\mathrm{CNCs}$ coating alone $\left(\mathrm{KP}_{\mathrm{O} 2}, \mathrm{KP}_{\mathrm{CO} 2}, \mathrm{ml} \mu \mathrm{m} \mathrm{m}^{-2} \mathrm{~d}^{-1} \mathrm{bar}^{-1}\right)$ were calculated using the following equations, ${ }^{27}$ assuming that the PET surface did not interact with the coating layer above, whose thickness is $L(\mu \mathrm{m})$, and that the interface between them negligibly affected the final permeation measure.

$$
\begin{aligned}
& \frac{L}{\mathrm{KP}_{\mathrm{O} 2}(\text { CNCs coating })}=\frac{1}{\mathrm{P}_{\mathrm{O} 2}(\text { coated PET film })}-\frac{1}{\mathrm{P}_{\mathrm{O} 2}(\mathrm{PET} \text { film })} \\
& \frac{L}{\mathrm{KP}_{\mathrm{CO} 2}(\mathrm{CNCs} \text { coating })}=\frac{1}{\mathrm{P}_{\mathrm{CO} 2}(\text { coated PET film })}-\frac{1}{\mathrm{P}_{\mathrm{CO} 2}(\mathrm{PET} \text { film })}
\end{aligned}
$$

Table 1. Surface tension parameters of the liquids used in contact angle determination (in $\mathrm{mJ} / \mathrm{m}^{2}$ ) at $20^{\circ} \mathrm{C}^{\left[25,26^{*}\right]}$

\begin{tabular}{lccc}
\hline Liquid & $\gamma_{\boldsymbol{l}}$ & $\gamma_{l}^{\boldsymbol{D}}$ & $\gamma_{l}^{\boldsymbol{P}}$ \\
\hline Milli-Q Water & 72.8 & 21.8 & 51.0 \\
Diiodomethane & 50.8 & 50.8 & 0 \\
Formamide $^{*}$ & 58.0 & 39.0 & 19.0 \\
\hline
\end{tabular}


From the isostatic permeation curves obtained (Figure 2), the diffusion coefficient $\left(D_{G}, \mathrm{~cm}^{2} \mathrm{~s}^{-1}\right)$ of each gas was estimated, according to the following equation ${ }^{28}$ :

$$
D_{G}=\frac{L^{2}}{7.2 \times t_{1 / 2}}
$$

where $L$ is the thickness $(\mathrm{cm})$ and $t_{1 / 2}(\mathrm{~s})$ is the time required to reach half of the maximum permeability value. Knowing the permeability and diffusion coefficients $\left(K P_{G}, D_{G}\right)$ of each gas, their solubilities $\left(S_{G}, \operatorname{bar}^{-1}\right)$ in the coating were estimated on the basis of:

$$
S_{G}=\frac{K P_{G}}{D_{G}}
$$

The oxygen permeability of the KP-CNC coated film was also measured at $23^{\circ} \mathrm{C}$ under $70,50,30$, 20 and $10 \% \mathrm{RH}$ on the coated side of the film.

\section{Statistical analysis}

All experiments and analyses were performed, at least, in triplicate. On the data, the standard deviation was always assessed and, because of the interest in comparing the CNCs extracted from two different raw materials, when appropriate, a $t$-test was applied, assuming independent and identically distributed samples. The significance of difference of the compared means was at $p \leq 0.05$.

\section{RESULTS}

\section{Raw material characterization}

Cotton linters are by-products of the oil mills, mechanically and chemically purified, characterized by thin and short fibres (length 2-6 mm, diameter 6-12 $\mu \mathrm{m}$ ). According to the provider's information they contain only small amounts of minerals and hemicellulose and, after purification, provide a cellulose content of around 99\%. The hardwood KP used to obtain the CNCs was analysed according to the current TAPPI methods, and the results are shown in Table 2. It was characterized on the basis of the amounts of $\alpha, \beta$ and $\gamma$ cellulose, lignin content and kappa number. $\alpha$-Cellulose is commonly considered the not-degraded, higher molecular weight cellulose fraction, $\beta$-cellulose indicates degraded cellulose, $\gamma$-cellulose mainly consists of hemicellulose, while the Kappa number, estimating the amount of chemicals required during bleaching of wood pulp, is approximately proportional to the residual lignin content of the pulp. The range for bleachable pulps is about 25-30, while higher values (45-90) are

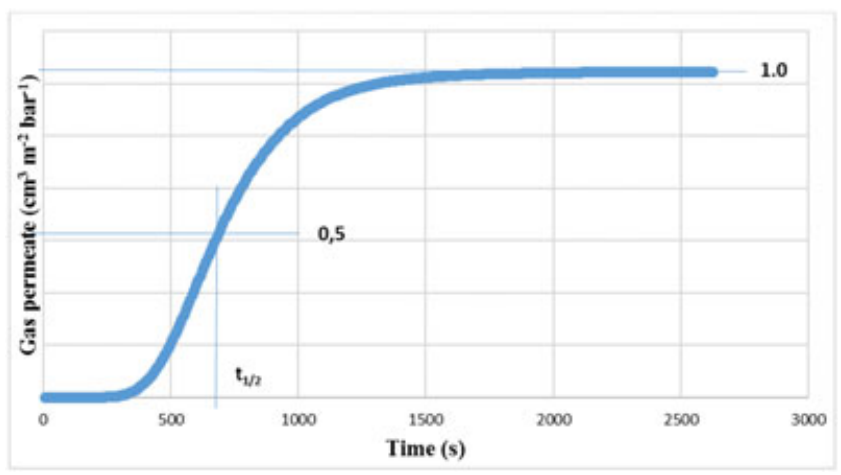

Figure 2. Gas permeation profile in isostatic method and $t_{1 / 2}$ identification. 
Table 2. K number and main constituents of the hardwood kraft pulp used.

\begin{tabular}{|c|c|c|c|c|c|}
\hline Kappa number & $\alpha$-Cellulose (\%) & $\beta$-Cellulose (\%) & $\gamma$-Cellulose $(\%)$ & Lignin $(\%)$ & Minerals (\%) \\
\hline - & - & - & - & - & - \\
\hline 35.5 & 79.9 & 0.37 & 12.52 & 7.9 & 0 \\
\hline- & - & - & - & - & - \\
\hline
\end{tabular}

typical for the more coarse manufacturing such as sack paper or corrugated fibreboard. The Kappa number of the pulp used in this work is 35.5 , a value consistent with the medium-high lignin content measured (about $8 \%$ ). The degraded cellulose ( $\beta$-cellulose) is limited, but, much more important, the hemicellulose content ( $\gamma$-cellulose) is high, denoting the complexity of the raw material selected.

\section{Characterization and comparison of cellulose nanocrystals obtained from the two raw materials}

The hydrolyzing-oxidative APS method used was effective in reducing the particle dimensions, providing a significant oxidation of native cellulose and giving satisfactory yields of $\mathrm{CNCs}$, which were assessed at $21.5 \%$ from KP and 50\% from CLs. The lower yield obtained from the pulp is due to the complex composition of this raw material and, in particular, to the lignin content which depletes part of the reactants used to extract and oxidize the CNCs. ${ }^{13,29}$ The reported yields, moreover, were estimated by a gravimetric method, and this does not exclude the possible presence of some residual, non-cellulosic, components in the KP-CNCs. The de-lignification process of KP, anyway, was quite fast, according to the observed colour change of the fibre dispersion during the process shown in Figure 3 and quite extensive, according to the disappearance of the absorbance peaks in the range $2800-3200 \mathrm{~cm}^{-1}$, which is pertinent to the lignin structure ${ }^{20}$ and shown in Figure 6. At the end of the process $(16 \mathrm{~h})$ and after the steps of purification and freeze drying, it was possible to collect enough CNCs for further characterization analysis and the coating process.

Cellulose nanocrystal morphology. The CNCs' dimensions were characterized in terms of their hydrodynamic diameter distribution by DLS measures, and in Figure 4, the comparison of CNCs obtained from KP and CLs is presented for the relative frequency of the intensity of scattered light. The results indicate an average hydrodynamic diameter which was quite similar for both samples, around $130-170 \mathrm{~nm}$, very close to previous results reported. ${ }^{12,30,31}$ It is well known that the hydrodynamic diameter is estimated assuming spherical and non-permeable particles, and it is not expected to be equal to the length of $\mathrm{CNC}$ rods, while it strongly correlates with particle lengths, generally resulting much shorter than the values estimated by microscopic techniques. ${ }^{32}$ A summary of the parameters obtained by the DLS analysis is reported in Table 3, and the comparison reveals quite different polydispersity indexes, which are higher for KP-CNCs, therefore indicative of a more complex morphology.

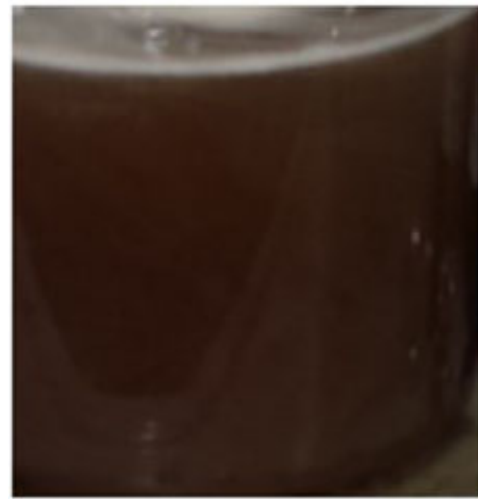

Time zero

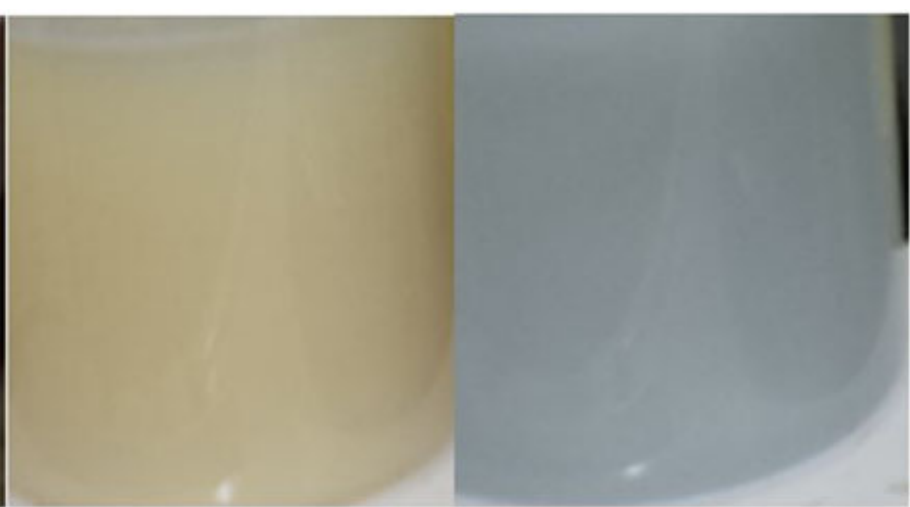

After 2 hours
After 12 hours

Figure 3. Lignin bleaching of kraft pulp during the APS process. 


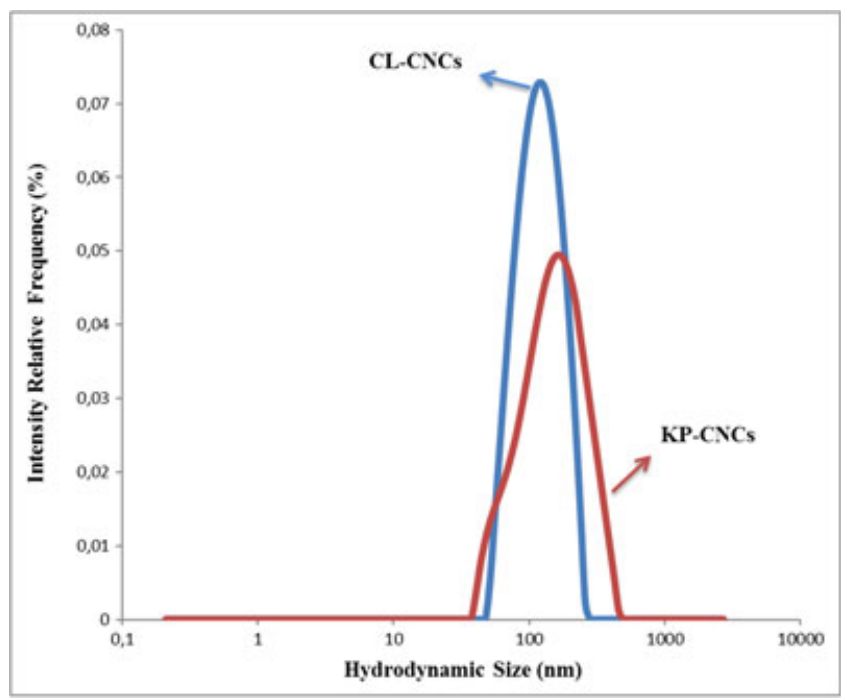

Figure 4. CNC hydrodynamic intensity-weighted size distributions obtained by DLS.

Actually, a polydispersity index of $10 \%$ is suggested as a limit above which DLS can no longer be interpreted accurately, ${ }^{33}$ and both types of CNCs showed higher values than this. Moreover, scattering intensities depend hugely (sixth power) on the particles' size; therefore, with bi- or multi-modal distributions, the peaks of bigger nano-particles are visible, while the smaller are underestimated. In fact, the TEM observations reveal important differences in terms of morphology of the two kinds of CNCs. Electron micrographs (see Figure 5) show only rod-like shapes for CL-CNCs, while shape and dimensions of KP-CNCs are composite, denoting both rod-like and many spherical nanoparticles. The presence of such spherical shapes cannot be attributed to the APS process used but, very likely, to the cellulose source, and, actually, several authors have already described spherical CNCs and related this morphology to the use of hydrochloric acid and/or possible alkaline pre-treatment. ${ }^{19,34-37}$ In particular, it is worth underlining that the kraft process is based on alkaline treatment of the wood and thus may be responsible for this complex morphology. In order to check the unusual morphology, we acquired a SEM image of the KP-CNCs, reported on the right side of Figure 5, which confirms the presence of both rod like and spherical nanoparticles, leading to a network that might be relevant for final performance of the coatings prepared.

Cellulose nanocrystal chemical characterization. Various chemical features were evaluated in order to compare the CNCs obtained from the lignocellulosic cellulose source, with those from CLs (Table 4). By means of light scattering techniques, besides the hydrodynamic diameter, an evaluation of the molecular mass of nano-particles was achieved by using a static light scattering method, while the Zeta potential and the conductivity of CNCs dispersion were assessed using an ELS method. Collecting the FTIR spectra of freeze dried CNCs in attenuated total reflectance mode, a check of the chemical structure and an evaluation of the degree of oxidation induced by the APS process were obtained. Zero

Table 3. Morphological information on CNCs from the two different raw materials (average values \pm s.d.).

\begin{tabular}{lccl}
\hline Property & CL-CNCs & KP-CNCs & $\begin{array}{c}\text { Difference assessed by } \\
\text { Student's } t \text {-test }(p=0.05)\end{array}$ \\
\hline Rod length (nm) by TEM & $117.6 \pm 16.6$ & $184 \pm 17.1$ & Significant \\
Rod diameter (nm) by TEM & $6.33 \pm 0.57$ & $7.11 \pm 1.02$ & Non significant \\
Sphere diameter (nm) by TEM & - & $31.75 \pm 7.1$ & - \\
Hydrodynamic diameter by DLS (nm) & $121.8 \pm 15.6$ & $167.9 \pm 2.5$ & Significant \\
Polydispersity index, & $20.3 \pm 3.39$ & $24.43 \pm 3.48$ & Non significant \\
\hline
\end{tabular}

Polydispersity defined as PDI $=(\sigma / \mathrm{D})^{2}$, is a measure of the width of particle size distribution. 


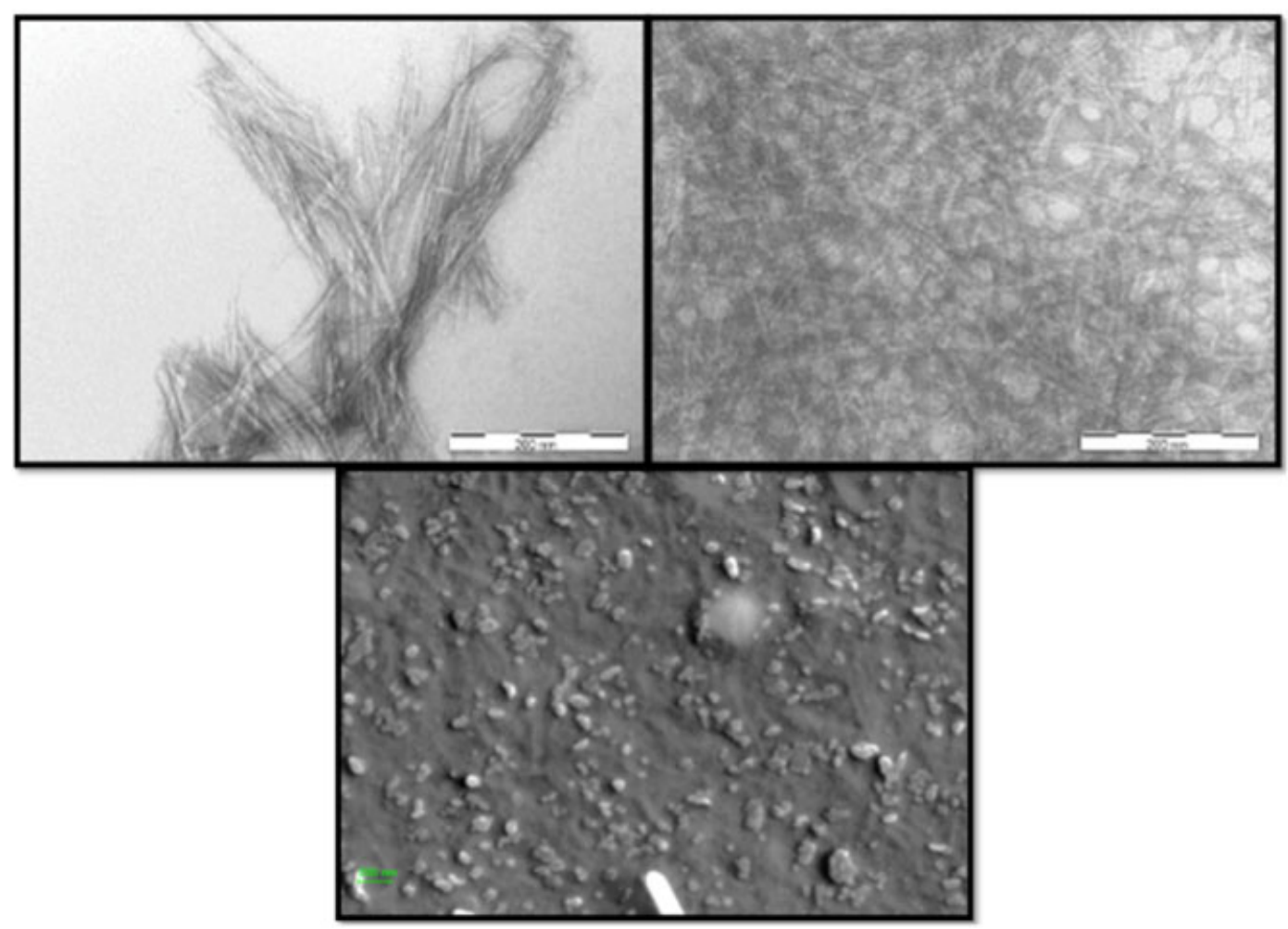

Figure 5. Electron micrographs of CNCs obtained from cotton linters (left) and kraft pulp (right) by TEM, and CNCs from Kraft pulp by SEM (centre, below).

shear viscosity $\left(\eta_{0}\right)$ of the suspension used for the coating in subsequent steps was calculated using Cross equation ${ }^{38}$ :

$$
\frac{\eta-\eta_{\infty}}{\eta_{0}-\eta_{\infty}}=\frac{1}{1+\left(K^{2} \cdot \dot{\gamma}^{2}\right)^{\frac{(1-n)}{2}}}=\frac{1}{1+(K \cdot \dot{\gamma})^{1-n}}
$$

Data used for the equation as standard shear viscosity versus shear rate have been derived by experimental complex viscosity versus angular frequency data using the Cox-Merz rule. In the Cross equation, $\eta_{0}$ represents zero shear viscosity, $\eta_{\infty}$ infinite shear viscosity, $\gamma$ is shear rate, $(1-n)$ is called Cross rate constant (with $n$ known as non-Newtonian behaviour index) and $\mathrm{K}$ is the Cross time

Table 4. Chemical features of CNCs from the two different raw materials (average values \pm s.d.).

\begin{tabular}{|c|c|c|c|}
\hline Property & CL-CNCs & $\mathrm{KP}-\mathrm{CNCs}$ & $\begin{array}{c}\text { Difference assessed } \\
\text { by Student's } t \text {-test }(p=0.05)\end{array}$ \\
\hline Zeta potential (mV) & $-44.7 \pm 1.1$ & $-40.1 \pm 0.8$ & Significant \\
\hline Conductivity $\left(\mathrm{mS} \mathrm{cm}^{-1}\right)$ & $0.095 \pm 0.024$ & $0.11 \pm 0.015$ & Non significant \\
\hline Degree of oxidation (DO) & 0.16 & 0.20 & - \\
\hline Molecular mass (kDa) & $1.15 \times 10^{6}$ & $3.86 \times 10^{5}$ & _- \\
\hline Viscosity $(\eta 0, \mathrm{~Pa} \mathrm{~s})$ & Non-detectable & $2.62 \times 10^{3}$ & - \\
\hline$T G A\left(T o,{ }^{\circ} \mathrm{C}\right)$ & 304.45 & 303.42 & - \\
\hline$T G A\left(T i,{ }^{\circ} \mathrm{C}\right)$ & 336.47 & 345.14 & - \\
\hline TGA $\left(\operatorname{Tmax},{ }^{\circ} \mathrm{C}\right)$ & 388.02 & 369.39 & - \\
\hline
\end{tabular}


constant. Finally, the thermal stability of CNCs from the two different sources was investigated using a thermogravimetric procedure (TGA).

$\mathrm{T}_{0}, \mathrm{~T}_{\mathrm{i}}$ and $\mathrm{T}_{\max }$ are three parameters usually indicated in the description of a thermal degradation process. Because cellulose KP-CNC exhibits a one-step degradation pathway, these three parameters are defined as, respectively, temperature in correspondence to the inflection point for the step, Ti, and temperatures at which the tangent in this point encounters the extensions of plateau regions when degradation starts, $\mathrm{T}_{0}$, and finishes, $\mathrm{T}_{\max }$.

Zeta potential value is an assessment of the electro-kinetic potential in colloid dispersions, being related to the degree of repulsion between ions of like charges and particle-particle interaction. It provides information about the particles' surface-solvent interface, and its measurement is key to understanding dispersion stability and aggregation phenomena, i.e. it is essential to know this for the potential use of $\mathrm{CNCs}$ as coatings for flexible packaging materials. Both of the CNCs produced exceed the value of 40 , assumed as a minimum essential to guarantee good stability of colloid dispersions. ${ }^{39}$ The lower value in the KP-CNCs' sample can be related to its higher viscosity, which affects the electrophoretic mobility in the electric field used for zeta potential assessment. KP-CNCs and CL-CNCs suspensions have very different rheological behaviours. KP-CNCs' suspension shows shear thinning behaviour, with a constant slope of viscosity in the frequency range considered and no Newtonian plateau at low shear rates: the slope of complex viscosity and of elastic and storage modulus is similar to the one observed when thickening agents are dispersed in fluids. ${ }^{40}$ Data registered at frequencies higher than $12 \mathrm{~Hz}$ were not reported because viscosity was under the detection limit of the instrument. The CL-CNCs' suspension shows very low viscosity, which becomes non-detectable using the cone-plate geometry used for measurements. In particular, they appear to have viscosities lower by from one to four orders of magnitude in the same conditions used for the KP-CNC suspension and a different behaviour in relation to the frequency applied. The higher viscosity of KP-CNCs, and their behaviour in relation to frequency, is inconsistent with the difference observed in the molecular mass (lower than CL-CNCs, see Table 4), but could be related to the composite morphology already noted for the nano-particles and to a residue of hemicellulose from the raw material. As the TEM microphotographs show, the spherical nanoparticles are entrapped into the network of rod-like CNCs, very likely giving a sort of rigidity to the system. The hemicelluloses, on the other hand, are well known as gluing substances and can strongly affect the viscosity. ${ }^{41}$ The conductivity values assessed on the two CNCs are similar and consistent with the degree of oxidation; i.e. they show a higher conductivity in the more oxidized nanoparticles. From the comparison of FTIR spectra (Figure 6), a confirmation of identical chemical structure of the two CNCs and a proof of lignin degradation were obtained.

The evaluation of the TGA values (Table 4 and Figure 7) confirms the possible presence of some contaminants in the KP-CNCs. In fact, even if the onset temperatures (To) are very close $\left(304.4^{\circ} \mathrm{C}\right.$ and $303.4^{\circ} \mathrm{C}$ for the CL-CNCs and KP-CNCs, respectively), the temperatures corresponding to the inflection point (Ti) and maximum value (Tmax) are quite different. In particular, the lower maximum temperature of nano-particles produced from KP, for which the CNCs undergo a most important degradation, can be explained by the presence of substances less thermostable than pure cellulose, suggesting that a better optimization of the fragmentation process and of purification steps are required.

\section{Characterization and comparison of poly(ethylene terephthalate) films coated with cellulose nanocrystals obtained from the two raw materials}

Chemical and physical features of the coated films. The coatings were realized on the same substrate (PET, $12 \mu \mathrm{m}$ thick) after the same activation step by corona treatment, with the two different CNC suspensions, and providing the same amount of cellulose nano-crystals per surface unit. Due to the different viscosities, however, the CL-CNC suspension was applied in one step, using a $8 \%(w / v)$ concentration, while the KP-CNC suspension was applied in two successive steps, using a $4 \%(w / v)$ concentration. Nevertheless, the final thicknesses obtained were quite similar (Table 5), and also the adhesion strength (evaluated as water solubility of the coating), evaluated by an empirical, but severe, method on the two coatings, showed no significant differences and provided indications of a good stability and consistency of both the coatings. The coefficients of friction (COF), estimated both as 


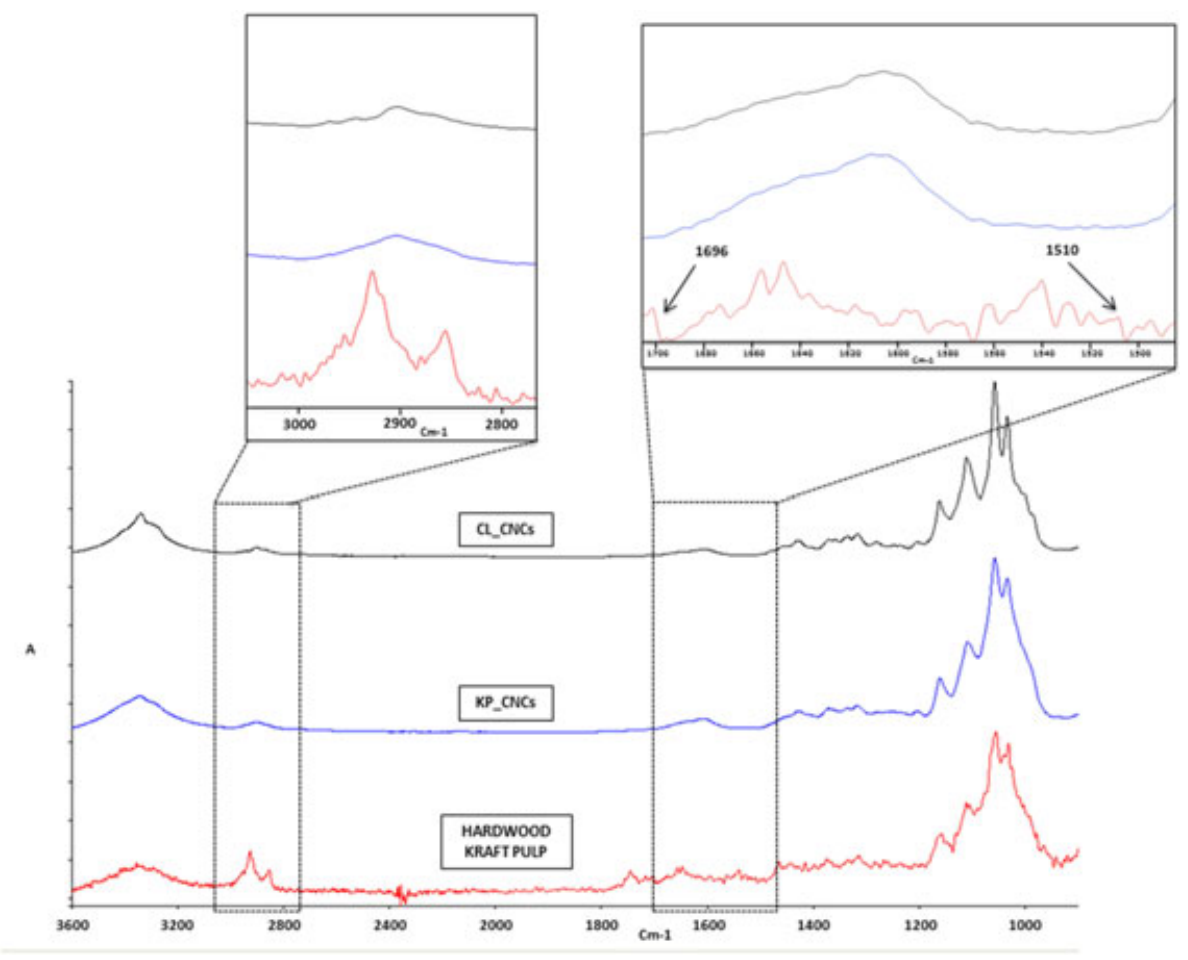

Figure 6. FTIR spectra of the CNCs for the evaluation of lignin removal.

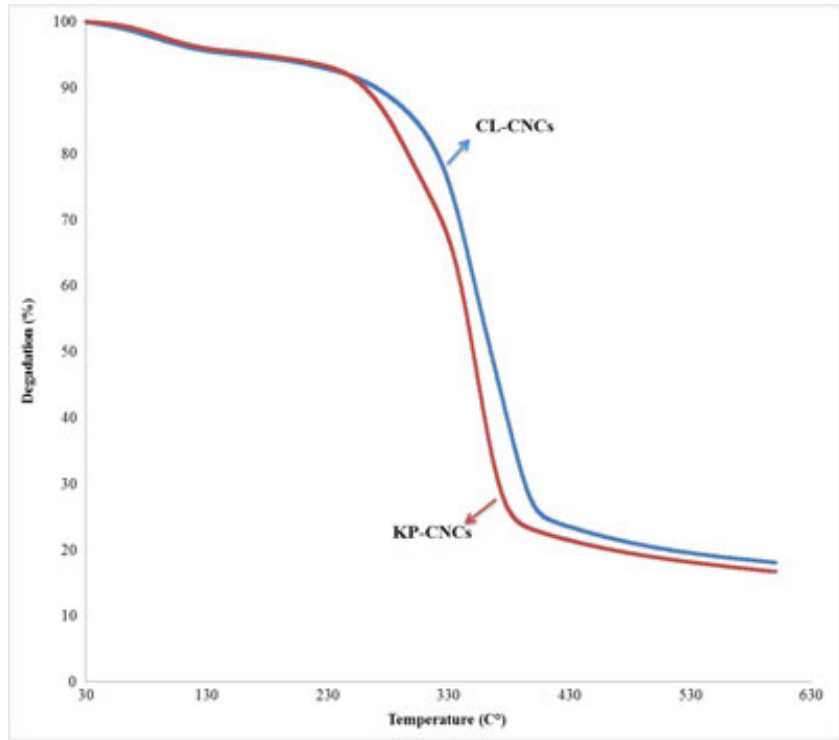

Figure 7. TGA plots, from 30 to $600^{\circ} \mathrm{C}$, of $\mathrm{CNCs}$ from cotton linters and kraft pulp in air.

dynamic and static values (Table 5), were a little higher than those obtained in previous papers ${ }^{12,30}$ when a lower amount of CNCs was used (7\%), but always much lower than that of the substrate alone. The corona-treated side of PET, in fact, shows much higher values in the 0.5-0.7 range (data not presented). Such difference in COF values is indicative of a well-distributed coating onto the substrate surface and is consistent with a good machinability of the coated films. KP-CNC-coated film had higher COF values than CL-CNCs, (significantly different) denoting once again some differences in the chemical nature of the coating, but the low standard deviations of the measures can be again 
Table 5. Some features of PET film coated with CNCs obtained from the two different raw materials (average values \pm s.d.).

\begin{tabular}{|c|c|c|c|}
\hline- & $\begin{array}{l}\text { PET coated } \\
\text { CL-CNCs }\end{array}$ & $\begin{array}{l}\text { PET coated } \\
\text { KP-CNCs }\end{array}$ & $\begin{array}{l}\text { Difference assessed by } \\
\text { Student's } t \text {-test }(p=0.05)\end{array}$ \\
\hline Coating thickness (nm) & $756.3 \pm 22.3$ & $746.8 \pm 89.5$ & Non significant \\
\hline Water resistance $(\%)$ & $49.2 \pm 3.3$ & $47.8 \pm 0.7$ & Non significant \\
\hline $\mathrm{COF}^{1}$ static & $0.35+0.02$ & $0.43+0.02$ & Significant \\
\hline $\mathrm{COF}^{1}$ dynamic & $0.26 \pm 0.02$ & $0.30 \pm 0.01$ & Significant \\
\hline Transparency (T\%) & $85.67 \pm 0.3$ & $81.7 \pm 1.1$ & Significant \\
\hline $\operatorname{Haze}(\%)$ & $1.89 \pm 0.1$ & $3.18 \pm 0.9$ & Significant \\
\hline $\mathrm{OCA}^{2}$ water & $23.6 \pm 4.9$ & $22.6 \pm 3.6$ & Non significant \\
\hline $\mathrm{OCA}^{2}$ diiodomethane & $27.7 \pm 3.5$ & $33.9 \pm 2.8$ & Non significant \\
\hline $\mathrm{OCA}^{2}$ formamide & $5.54 \pm 0.7$ & $12.9 \pm 3.8$ & Significant \\
\hline $\mathrm{SFE}^{3}\left(\mathrm{~mJ} \mathrm{~m}^{-2}\right)$ & 68.85 & 68.18 & 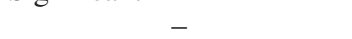 \\
\hline $\mathrm{SFE}_{2}^{3}$ polar part $\left(\mathrm{mJ} \mathrm{m}^{-2}\right)$ & 29.37 & 31.20 & - \\
\hline $\mathrm{SFE}^{3}$ dispersive part $\left(\mathrm{mJ} \mathrm{m}^{-2}\right)$ & 38.49 & 36.98 & - \\
\hline
\end{tabular}

${ }^{1}$ Coefficients of friction.

${ }^{2}$ Optical contact angles.

${ }^{3}$ Surface energies.

assumed as proof of uniform covering of the substrate, thus, good coating aptitudes of CNC suspensions.

The optical properties evaluated on the coated films (haze and transparency) showed significant differences between the KP-CNCs and CL-CNC-coated PET, with lower transparency and higher haze values for the coating obtained from lignocellulosic raw material, but this was still acceptable for practical purpose. It is also worth mentioning the clearly visible iridescence on the surface of KP-CNC-coated film, typical behaviour of one-dimension crystallinity. ${ }^{42}$

An extensive evaluation of surface properties was conducted with the aim of characterizing the two coatings, and with a view to developing a laminating step, needed to protect and make sealable the coated film developed. The static contact angles of the two coatings (Table 5) were quite similar for water and the apolar solvent (diiodomethane), showing non-significant differences, but were different for the polar, organic solvent (formamide). These results confirm previous data, ${ }^{12,30}$ highlighting the higher wettability of these coatings towards polar solvents (even organic ones) in comparison with bare film (PET showed 57.4 and 39.5 for water and formamide, respectively) and to CNCs obtained by the traditional $\mathrm{H}_{2} \mathrm{SO}_{4}$ hydrolyzing process. ${ }^{12}$ The higher affinity of these coatings for water and polar solvents is also well demonstrated by the surface energy (SFE) values and their components. About $68 \mathrm{~mJ} \mathrm{~m}^{-2}$ (see Table 5) is a quite high SFE value, much higher than typical values of PET bare film. ${ }^{30,43}$ The substrate used, in fact, has SFE around $45 \mathrm{~mJ} \mathrm{~m}^{-2}$ and a very small polar component (less than $5 \mathrm{~mJ} \mathrm{~m}^{-2}$ ). These are classical achievements when hydrophilic polymers are considered, $10,30,43,44$ but, in this case, the powerful action of the APS reagent in the oxidation of cellulose is also to be underlined in evaluating these high values of SFE recorded.

Diffusional properties. The overall results obtained in the comparison of the CNC coatings obtained using a pure cellulosic source (CL) and a lignocellulosic raw material (KP) encouraged the potential use of KP-CNC coating as an effective gas barrier coating, in real applications, as an intermediate layer of possible laminate structures. Therefore, the investigation proceeded with a deep analysis of gas permeability properties of the PET film coated with the CNCs from the hardwood KP. Previous studies clearly demonstrated the effectiveness of cellulose nano-crystals coatings, as the gas barrier layer in possible laminated flexible structures, ${ }^{10,12,30,45-48}$ showing oxygen gas permeability values much lower than the ones currently provided by synthetic polymers, but only few data are available so far about $\mathrm{CO}_{2}$ permeability, thermal and relative humidity sensitivity of such nano-coatings. At first, the $\mathrm{CO}_{2}$ and $\mathrm{O}_{2}$ permeability of un-coated and KP-CNCs coated PET films were measured in a range of temperatures from 30 to $50^{\circ} \mathrm{C}$, and the diffusional properties of the coating alone were calculated. In Figure 8 , the $\mathrm{CO}_{2}$ and $\mathrm{O}_{2}$ permeability of PET film $(12 \mu \mathrm{m})$ and $\mathrm{CNC}$ coating $(0.74 \mu \mathrm{m})$ are presented in a log diagram ( $\mathrm{LnP}$ vs $1 / \mathrm{T})$, together with the apparent activation energies of permeabilities (Ea), 


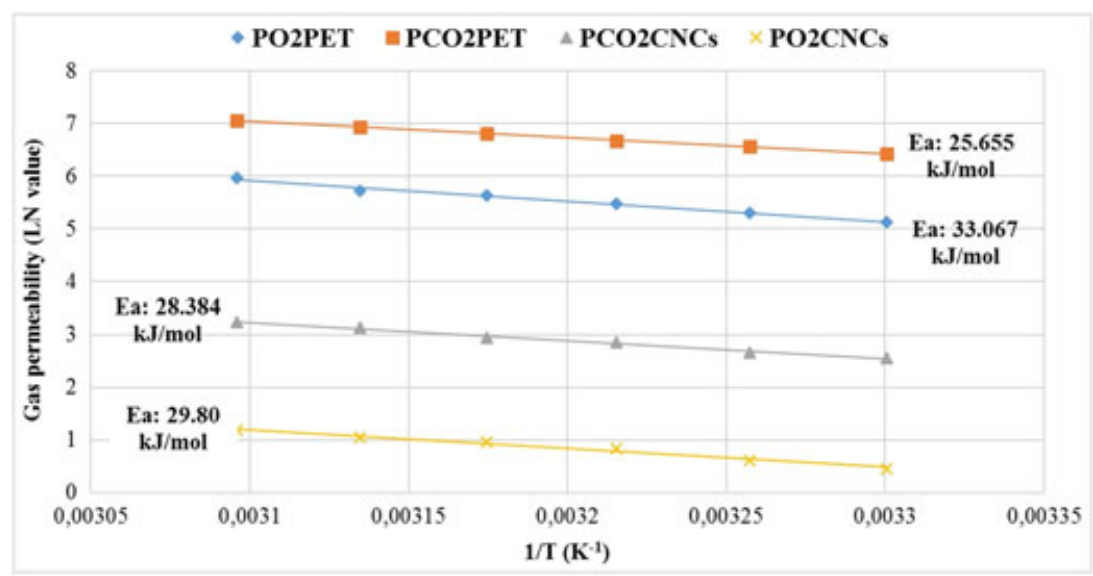

Figure 8. Arrhenius plot of oxygen and carbon dioxide permeabilities in PET and KP-CNC coating. The permeability measures were all conducted at $0 \% \mathrm{RH}$.

estimated according to the Arrhenius equation. The superior barrier properties of CNCs coating are well evident, and it is worth noting that $\mathrm{P}_{\mathrm{CO} 2} \mathrm{CNCs}$ is about $4 \log (\mathrm{Ln})$ lower than $\mathrm{P}_{\mathrm{CO} 2} \mathrm{PET}$, while $\mathrm{P}_{\mathrm{O} 2} \mathrm{CNCs}$ is more than 5 log lower than $\mathrm{P}_{\mathrm{O} 2} \mathrm{PET}$. Moreover, the comparison of activation energies is also of interest, showing that the Ea of $\mathrm{O}_{2}$ permeation is higher in PET than in CNCs, while for carbon dioxide it is the opposite. This means that gas diffusion through the biopolymer coating is different in comparison with the diffusion through PET film, and the difference particularly affects oxygen diffusion leading to a significantly lower thermal sensitivity of permeability in the nanocrystals. The concepts of 'free volume' and cooperative movement of gas molecules and polymer chains are generally considered useful to explain gas permeability and its thermal sensitivity, ${ }^{49}$ and it is worth noting that the free volume inside KP-CNC coating, as well as the chain mobility, must be affected by the particular morphology observed in these nano-particles, where the voids inside a network of rod-like crystals are filled by spherical particles.

In Table 6, the permeability coefficients $\left(\mathrm{KP}_{\mathrm{O} 2}\right.$ and $\left.\mathrm{KP}_{\mathrm{CO} 2}\right)$, calculated for the bare PET film and the $\mathrm{CNC}$ coating, are presented at the minimum and maximum temperatures tested (at $0 \% \mathrm{RH}$ ), together with diffusion and solubility coefficients. The barrier property provided by the coating is evident and impressive. The $\mathrm{KP}_{\mathrm{O} 2}$ and $\mathrm{KP}_{\mathrm{CO} 2}$ of $\mathrm{KP}$ CNCs coating are a thousand times lower than that of the substrate, showing values which are 8-10 times lower than those of synthetic barrier polymers such as EVOH or PVOH and 50-60 times lower than O-MXD6 or PVDC. Such low values are mainly due to the strongly reduced diffusion coefficients which, at both the temperatures, are about onethousandth of what has been measured in PET for oxygen and less than three-thousandth for carbon dioxide. Solubility, on the contrary, is not dramatically reduced, sustaining the hypothesis of a relevant effect of the complex structure revealed for $\mathrm{CNCs}$ coming from the lignocellulosic raw material.

Table 6. Permeability, diffusion and solubility coefficients of oxygen and carbon dioxide, in PET and KP$\mathrm{CNC}$ coating. The permeability measures were all conducted at $0 \% \mathrm{RH}$.

\begin{tabular}{lcccccc}
\hline & $\begin{array}{c}\mathrm{KP}_{\mathrm{G}} \text { at } 30^{\circ} \mathrm{C} \\
\left(\mathrm{cm}^{3} \mu \mathrm{m}^{-2}\right. \\
\left.\mathrm{bar}^{-1} \mathrm{~d}^{-1}\right)\end{array}$ & $\begin{array}{c}\mathrm{KP}_{\mathrm{G}} \text { at } 50^{\circ} \mathrm{C} \\
\left(\mathrm{cm}^{3} \mu \mathrm{m} \mathrm{m}^{-2}\right. \\
\left.\mathrm{bar}^{-1} \mathrm{~d}^{-1}\right)\end{array}$ & $\begin{array}{c}\mathrm{D}_{\mathrm{G}} \text { at } 30^{\circ} \mathrm{C} \\
\left(\mathrm{cm}^{2} \mathrm{~s}^{-1}\right)\end{array}$ & $\begin{array}{c}\mathrm{D}_{\mathrm{G}} \text { at } 50^{\circ} \mathrm{C} \\
\left(\mathrm{cm}^{2} \mathrm{~s}\right)\end{array}$ & $\begin{array}{c}\mathrm{S}_{\mathrm{G}} \text { at } 30^{\circ} \mathrm{C} \\
\left(\mathrm{bar}^{-1}\right)\end{array}$ & $\begin{array}{c}\mathrm{S}_{\mathrm{G}} \text { at } 50^{\circ} \mathrm{C} \\
\left(\mathrm{bar}^{-1}\right)\end{array}$ \\
\hline- & - & - & - & - & - & - \\
$\mathrm{O}_{2}$ in PET & 2004 & 4694 & $3.78 \mathrm{E}-10$ & $4.23 \mathrm{E}-10$ & 0.612 & 1.282 \\
$\mathrm{O}_{2}$ in CNCs & 1.2 & 2.5 & $4.07 \mathrm{E}-13^{1}$ & $5.32 \mathrm{E}-13$ & $0.341^{1}$ & 0.544 \\
$\mathrm{CO}_{2}$ in PET & 7450 & 14004 & $2.91 \mathrm{E}-10$ & $4.46 \mathrm{E}-10$ & 2.966 & 3.630 \\
$\mathrm{CO}_{2}$ in CNCs & 9.7 & 19.1 & $7.81 \mathrm{E}-13$ & $1.22 \mathrm{E}-12$ & 1.44 & 1.82 \\
\hline
\end{tabular}

${ }^{1}$ Values collected at $34^{\circ} \mathrm{C}$. 


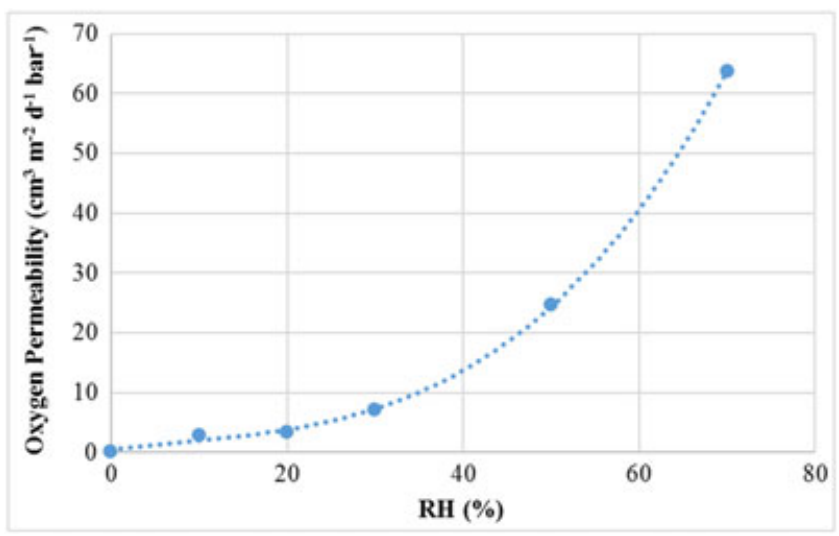

Figure 9. Oxygen permeability of $\mathrm{KP}-\mathrm{CNC}$-coated PET film at $23^{\circ} \mathrm{C}$, as function of relative humidity on the coated side.

The high gas barrier assessed is, at the same time, proof of barrier properties of the nanoparticles, as well as of the uniformity of the thin coating realized onto the PET film, suggesting a realistic opportunity for developing coating processes based on these kinds of CNCs. In any case, it is clear that this potential bio-barrier has to be protected from moisture absorption by a hydrophobic layer, which could also provide sealability to the final structure. In fact, the moisture sensitivity of the CNC coating is quite high, as Figure 9 shows, leading to an exponential increase of oxygen permeability when the relative humidity increases on the coated side. However, the loss of gas barrier properties is reversible, and if a drying step is provided to the coated film (data not shown), the permeability returns to the original, low values. This point is of relevant importance and is currently under deeper investigation.

\section{CONCLUSIONS}

The results obtained highlight that is possible to produce high performing coatings for common packaging materials, starting from inexpensive, largely available and renewable raw materials and by-products. The CNCs, easily obtained from the hardwood KP, were able to deliver, in the form of a thin coating onto a PET film, a surprisingly high oxygen and carbon dioxide barrier, which was just slightly affected by the temperature increase, at $0 \% \mathrm{RH}$. Even if in this work the gas barrier properties were mainly focused upon, it is well known that the CNCs can provide or enhance other interesting properties (mechanical, optical), and that CNCs can be used as templates to provide various forms of activity, such as antioxidant or antimicrobial, to the packaging materials. ${ }^{8}$ Therefore, it seems really appropriate to proceed with this line of research, addressed to increasing the sustainability of packaging materials, making it possible to put into practice concepts of circular economy or industrial symbiosis. In the particular case considered in this work, i.e. the production of plastic film coatings based on CNCs from lignocellulosics coming from the paper industries, the APS process seems really promising, leading to a satisfactory yield and a good lignin removal. However, a 'case by case' approach is advisable, to take into account individual differences in the cellulosic sources and in order to possibly adjust the process variables.

\section{ACKNOWLEDGEMENTS}

The authors wish to acknowledge Dr. Giorgio Capretti of INNOVHUB-SSI, Milan, for his scientific support. Mr. Alessio Busi, post-graduate Master student in the University of Milan, and Mr. Gerald Perry E. Marin, post-graduate Master student in Lund University, are strongly acknowledged for their unrivaled technical support. Finally, TUBITAK, the Scientific and Technological Research Council of Turkey, is 
warmly thanked for its support. This reserch has received funding from European Union's Horizon 2020 research and innovation program under grant agreement number: 720326.

\section{REFERENCES}

1. Keijsers ERP, Y1lmaz G, van Dam JEG. The cellulose resource matrix. Carbohydrate Polymers 2013; 93(1): 9-21 DOI: https://doi.org/10.1016/j.carbpol.2012.08.110.

2. Moon RJ, Martini A, Nairn J, Simonsen J, Youngblood J. Cellulose nanomaterials review: structure, properties and nanocomposites. Chemical Society Reviews 2011; 40(7): 3941-3994 DOI: https://doi.org/10.1039/c0cs00108b.

3. Nashar DEE, Abd-El-Messieh SL, Basta AH. Newsprint paper waste as a fiber reinforcement in rubber composites. Journal of Applied Polymer Science 2004; 91(5): 3410-3420 DOI: https://doi.org/10.1002/app.13726.

4. Shill K, Padmanabhan S, Xin Q, Prausnitz JM, Clark DS, Blanch HW. Ionic liquid pretreatment of cellulosic biomass: enzymatic hydrolysis and ionic liquid recycle.

5. Habibi Y, Lucia LA, Rojas OJ. Cellulose nanocrystals: chemistry, self-assembly, and applications. Chemical Reviews 2010; 110(6): 3479-3500 DOI: https://doi.org/10.1021/Cr900339w.

6. Eichhorn SJ, Dufresne A, Aranguren M et al. Review: current international research into cellulose nanofibres and nanocomposites. Journal of Materials Science 2010; 45(1): 1-33 https://doi.org/10.1007/s10853-009-3874-0.

7. Li F, Mascheroni E, Piergiovanni L. The potential of nanocellulose in the packaging field: a review. Packaging Technology and Science 2015; 28(6): 475-508 https://doi.org/10.1002/pts.2121.

8. Khan A, Huq T, Khan RA, Riedl B, Lacroix M. Nanocellulose-based composites and bioactive agents for food packaging. Critical Reviews in Food Science and Nutrition 2014; 54(2): 163-174 https://doi.org/10.1080/ 10408398.2011.578765.

9. Nair SS, Zhu J, Deng Y, Ragauskas AJ. High performance green barriers based on nanocellulose. Sustainable Chemical Processes 2014; 2(1): 1-7 https://doi.org/10.1186/s40508-014-0023-0.

10. Li F, Biagioni P, Finazzi M, Tavazzi S, Piergiovanni L. Tunable green oxygen barrier through layer-by-layer self-assembly of chitosan and cellulose nanocrystals. Carbohydrate Polymers 2013; 92(2): 2128-2134 https://doi.org/10.1016/j. carbpol.2012.11.091.

11. Leung A, Hrapovic S, Lam E et al. Characteristics and properties of carboxylated cellulose nanocrystals prepared from a novel one-step procedure. Small 2011; 7(3): 302-305 https://doi.org/10.1002/smll.201001715.

12. Mascheroni E, Rampazzo R, Ortenzi MA et al. Comparison of cellulose nanocrystals obtained by sulfuric acid hydrolysis and ammonium persulfate, to be used as coating on flexible food-packaging materials. Cellulose 2016; 23(1): 779-793 https://doi.org/10.1007/s10570-015-0853-2.

13. Leung CW, Luong JHT, Hrapovic S, Lam E, Liu Y, Male KB, Mahmoud K, Rho D. Cellulose nanocrystals from renewable biomass. Google Patents: 2012;

14. Rowell R, Young R, Rowell J. Paper and composites from agro-based resources, 1997. Ch 7 pp. 257.

15. Technical Association of the Pulp and Paper Industry. T 203 om-88, Alpha-, beta-, and gamma-cellulose in pulp. In Fibrous Materials and Pulp Testing. TAPPI Test Methods Vol. 1. TAPPI Press: Atlanta, GA, 1991.

16. Sluiter A, Hames B, Ruiz R et al. Determination of structural carbohydrates and lignin in biomass. Laboratory analytical procedure 2008: 1617.

17. Technical Association of the Pulp and Paper Industry. Kappa Number of pulp. In TAPPI Standard T 236. TAPPI PRESS: Atlanta, Ga, 1976.

18. Habibi Y, Chanzy H, Vignon M. TEMPO-mediated surface oxidation of cellulose whiskers. Cellulose 2006; 13(6): 679-687 https://doi.org/10.1007/s10570-006-9075-y.

19. Cheng M, Qin Z, Liu Y et al. Efficient extraction of carboxylated spherical cellulose nanocrystals with narrow distribution through hydrolysis of lyocell fibers by using ammonium persulfate as an oxidant. Journal of Materials Chemistry A 2014; 2 (1): 251-258 https://doi.org/10.1039/C3TA13653A.

20. Stark NM, Yelle DJ, Agarwal UP. Techniques for characterizing lignin. In Lignin in Polymer Composites. William Andrew Publishing, 2016; 49-66.

21. Debye P, Anacker EW. Micelle shape from dissymmetry measurements. The Journal of Physical Chemistry 1951; 55(5): 644-655 https://doi.org/10.1021/j150488a003.

22. Mazeau K, Heux L. Molecular dynamics simulations of bulk native crystalline and amorphous structures of cellulose. The Journal of Physical Chemistry B 2003; 107(10): 2394-2403 https://doi.org/10.1021/jp0219395.

23. Salimi A. Characterization of nano scale adhesion at solid surface of oxidized PP wax/PP blends. International Journal of Adhesion and Adhesives 2012; 33: 61-66.

24. Kutnar A, Kamke F, Petrič M, Sernek M. The influence of viscoelastic thermal compression on the chemistry and surface energetics of wood. Colloids and Surfaces A: Physicochemical and Engineering Aspects 2008; 329(1): 82-86.

25. van Oss CJ. Long-range and short-range mechanisms of hydrophobic attraction and hydrophilic repulsion in specific and aspecific interactions. Journal of Molecular Recognition 2003; 16(4): 177-190.

26. Dann JR. Forces involved in the adhesive process. Journal of Colloid and Interface Science 1970; 32(2): 302-320 https:// doi.org/10.1016/0021-9797(70)90054-8.

27. Crank J. The Mathematics of Diffusion. Oxford university press, 1979.

28. Hernandez RJ, Gavara R. Plastics Packaging: Methods for Studying Mass Transfer Interactions: A Literature Review. Pira International: 1999; 
29. Springer EL, Minor JL. Delignification of lignocellulosic materials with monoperoxysulfuric acid. Google Patents: 1991;

30. Li F, Biagioni P, Bollani M, Maccagnan A, Piergiovanni L. Multi-functional coating of cellulose nanocrystals for flexible packaging applications. Cellulose 2013; 20(5): 2491-2504 https://doi.org/10.1007/s10570-013-0015-3.

31. Anglès MN, Dufresne A. Plasticized starch/tunicin whiskers nanocomposite materials. 2. Mechanical behavior. Macromolecules 2001; 34(9): 2921-2931 https://doi.org/10.1021/ma001555h.

32. Boluk Y, Zhao L, Incani V. Dispersions of nanocrystalline cellulose in aqueous polymer solutions: structure formation of colloidal rods. Langmuir 2012; 28(14): 6114-6123 https://doi.org/10.1021/la2035449.

33. Baalousha M, Lead J. Rationalizing nanomaterial sizes measured by atomic force microscopy, flow field-flow fractionation, and dynamic light scattering: sample preparation, polydispersity, and particle structure. Environmental Science \& Technology 2012; 46(11): 6134-6142.

34. Zhang J, Elder TJ, Pu Y, Ragauskas AJ. Facile synthesis of spherical cellulose nanoparticles. Carbohydrate Polymers 2007; 69(3): 607-611 https://doi.org/10.1016/j.carbpol.2007.01.019.

35. Lu P, Hsieh YL. Preparation of rod-like, network-structured, and spherical cellulose nanocrystals with excellent thermal and mechanical properties. Abstracts of Papers of the American Chemical Society 2009: 237.

36. Wang N, Ding EY, Cheng RS. Thermal degradation behaviors of spherical cellulose nanocrystals with sulfate groups. Polymer 2007; 48(12): 3486-3493 https://doi.org/10.1016/j.polymer.2007.03.062.

37. Lu P, Hsieh YL. Preparation and properties of cellulose nanocrystals: rods, spheres, and network. Carbohydrate Polymers 2010; 82(2): 329-336 https://doi.org/10.1016/j.carbpol.2010.04.073.

38. Cross MM. Rheology of non-Newtonian fluids: a new flow equation for pseudoplastic systems. Journal of Colloid Science 1965; 20(5): 417-437 https://doi.org/10.1016/0095-8522(65)90022-X.

39. Hanaor D, Michelazzi M, Leonelli C, Sorrell CC. The effects of carboxylic acids on the aqueous dispersion and electrophoretic deposition of $\mathrm{ZrO}_{2}$. Journal of the European Ceramic Society 2012; 32(1): 235-244 https://doi.org/ 10.1016/j.jeurceramsoc.2011.08.015.

40. Manrique YJ, Sparkes AM, Cichero JAY et al. Oral medication delivery in impaired swallowing: thickening liquid medications for safe swallowing alters dissolution characteristics. Drug Development and Industrial Pharmacy 2016; 42 (9): 1537-1544 https://doi.org/10.3109/03639045.2016.1151033.

41. Fitt LE, Pienkowski JJ, Wallace JR. Starch-hemicellulose adhesive for high speed corrugating. Google Patents: 1994;

42. Salas C, Nypelö T, Rodriguez-Abreu C, Carrillo C, Rojas OJ. Nanocellulose properties and applications in colloids and interfaces. Current Opinion in Colloid \& Interface Science 2014; 19(5): 383-396.

43. Introzzi L, JMa F-A, Cozzolino CA et al. "Wetting enhancer" pullulan coating for antifog packaging applications. ACS Applied Materials \& Interfaces 2012; 4(7): 3692-3700.

44. Nuraje N, Asmatulu R, Cohen RE, Rubner MF. Durable antifog films from layer-by-layer molecularly blended hydrophilic polysaccharides. Langmuir 2010; 27(2): 782-791.

45. Frounchi M, Dourbash A. Oxygen barrier properties of poly(ethylene terephthalate) nanocomposite films. Macromolecular Materials and Engineering 2009; 294(1): 68-74 https://doi.org/10.1002/mame.200800238.

46. Fukuya MN, Senoo K, Kotera M, Yoshimoto M, Sakata O. Enhanced oxygen barrier property of poly(ethylene oxide) films crystallite-oriented by adding cellulose single nanofibers. Polymer 2014; 55(22): 5843-5846 https://doi.org/10.1016/j. polymer.2014.09.003.

47. Minelli M, Baschetti MG, Doghieri F et al. Investigation of mass transport properties of microfibrillated cellulose (MFC) films. Journal of Membrane Science 2010; 358(1-2): 67-75 https://doi.org/10.1016/j.memsci.2010.04.030.

48. Aulin C, Gallstedt M, Lindstrom T. Oxygen and oil barrier properties of microfibrillated cellulose films and coatings. Cellulose 2010; 17(3): 559-574 https://doi.org/10.1007/s10570-009-9393-y.

49. Mokwena KK, Tang J. Ethylene vinyl alcohol: a review of barrier properties for packaging shelf stable foods. Critical Reviews in Food Science and Nutrition 2012; 52(7): 640-650 https://doi.org/10.1080/10408398.2010.504903. 